\title{
D rosophila Cyclin B3 is required for female fertility and is dispensable for mitosis like Cyclin B
}

\author{
Henning W. Jacobs, Jürgen A. Knoblich, ${ }^{1}$ and Christian F. Lehner ${ }^{2}$ \\ Department of Genetics, University of Bayreuth, 95440 Bayreuth, Germany
}

\begin{abstract}
Cyclin B3 has been conserved during higher eukaryote evolution as evidenced by its identification in chicken, nematodes, and insects. We demonstrate that Cyclin B3 is present in addition to Cyclins A and B in mitotically proliferating cells and not detectable in endoreduplicating tissues of D rosophila embryos. Cyclin B3 is coimmunoprecipitated with Colk1(Cdc2) but not with Colk2(Cdc2c). It is degraded abruptly during mitosis like Cyclins A and B. In contrast to these latter cyclins, which accumulate predominantly in the cytoplasm during interphase, Cyclin B3 is a nuclear protein. Genetic analyses indicate functional redundancies. Double and triple mutant analyses demonstrate that Cyclins A, B, and B3 cooperate to regulate mitosis, but surprisingly single mutants reveal that neither Cyclin B3 nor Cyclin B is required for mitosis. However, both are required for female fertility and Cyclin B also for male fertility.
\end{abstract}

[Key Words: Cyclin B3; Cyclin B; Cyclin A; Cdk; Drosophila; mitosis; endoreduplication]

Received June 24, 1998; revised version accepted August 11, 1998.

Cell cycle transitions in higher eukaryotes are controlled by a number of different cyclin-dependent kinases (cdks). $\mathrm{Cdk1}$ (cdc2) binds to A- and B-type cyclins and functions primarily in the control of $M$ phase. These cyclins are distinguished by characteristic signature sequences within the cyclin box, the conserved cdk-binding domain present in all cyclins. A- and B-type cyclins have also a destruction box, a motif of $\sim 9$ amino acids required to target the cyclins to ubiquitin-dependent degradation during mitosis (Glotzer et al. 1991; King et al. 1996a,b).

The precise function of the various A- and B-type cyclins (Fig. 1A) is not understood. Two different A-type cyclins appear to be present in vertebrates as suggested by the identification of two conserved genes in both Xenopus and mouse (Howe et al. 1995; Sweeney et al. 1996). These two genes have distinct developmental expression patterns. Moreover, although Xenopus cyclin A1 is expressed primarily in early embryos and binds exclusively to cdk1, compl exes with both cdk 1 and cdk2 are observed in the case of cyclin A2, which is expressed during later developmental stages (Howe et al. 1995). The single known Drosophila Cyclin A homolog is expressed throughout development in all proliferating cells and is found in complexes with $\mathrm{Cdk} 1(\mathrm{Cdc} 2)$ but not with $\mathrm{Cdk} 2(\mathrm{Cdc} 2 \mathrm{c}$ ), at least during embryogenesis (Knoblich et

1Present address: Research Institute of Molecular Pathology (IMP), A-1030 Vienna, Austria.

${ }^{2}$ Corresponding author.

E-MAIL chle@uni-bayreuth.de; FAX 49921552710. al. 1994). Cyclin A genes have also been identified in Caenorhabditis el egans (Kreutzer et al. 1995), but no obvious homolog is present in yeast.

B-type cyclins are present in both yeast and higher eukaryotes. The six B-type cyclins of budding yeast (CLB1, CLB2, CLB3, CLB4, CLB5, CLB6), and the three of fission yeast $\left(\mathrm{CdCl}^{+}, \mathrm{Cigl}^{+}\right.$, and $\left.\mathrm{cig} 2^{+}\right)$, are more closely related to each other than to B-type cyclins from metazoan species (Fig. 1A). Although a single cyclin B gene has been found in invertebrate species, a pair of very closely related B-type cyclins is present in vertebrates. These vertebrate cycl ins B1 and B2 differ in their subcelIular local ization (Pines and Hunter 1991; Jackman et al. 1995), but distinct functions have yet to be discovered.

Cyclin B3, a novel cyclin with as yet unknown functions, has been identified recently in chicken, C. el egans, and Drosophila (Gallant and Nigg 1994; Kreutzer et al. 1995; Sigrist et al. 1995; this paper). Although cyclin B3 has some B-type signature sequences, it also shares a number of similarities with A-type cyclins. Chicken cyclin B3 can associate with human colk2 raising the possibility that it might function in the regulation of $\mathrm{S}$ phase (Gal lant and N igg 1994). To address the functi onal special ization, we have generated null mutations in the Drosophila genes Cyclin B and Cyclin B3. Surprisingly, neither gene is essential for viability in contrast to the previously anal yzed Cyclin A gene (Lehner and O'Farrell 1989). Double and triple mutant analyses, however, demonstrate that all these cyclin types cooperate during mitosis. 


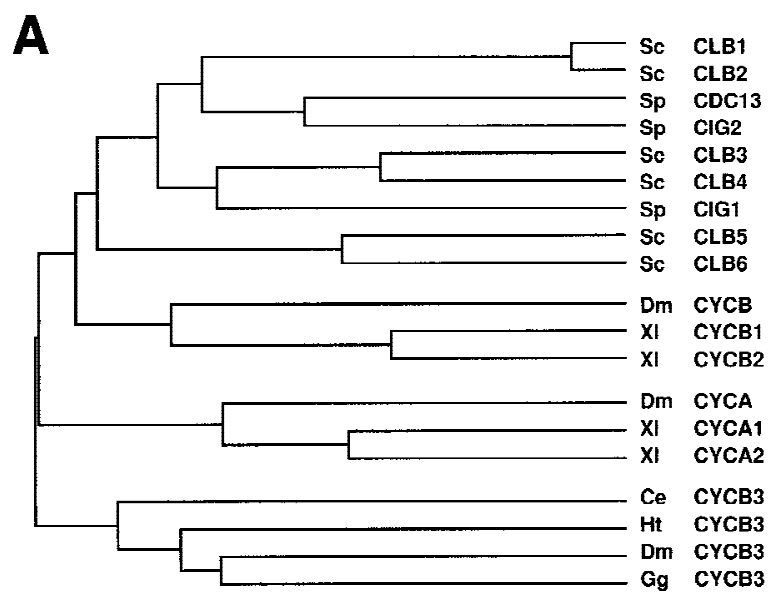

B

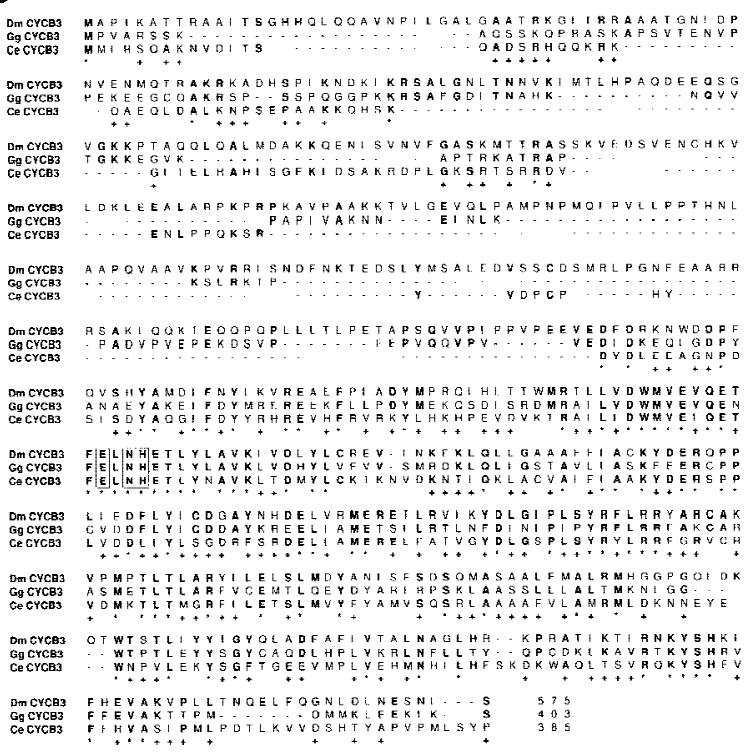

Figure 1. Cyclin B3 is conserved in metazoans. (A) The cyclin box sequences of A-, B-, and B3-type cyclins from budding yeast (Sc), fission yeast $(\mathrm{Sp}), \mathrm{C}$. el egans $(\mathrm{Ce})$, leech $(\mathrm{Ht})$, Drosophila $(\mathrm{Dm})$, Xenopus $(\mathrm{XI})$, and chicken $(\mathrm{Gg})$ were compared using CLUSTAL from the PCGENE software package. Although all yeast cyclins form a group most closely related to metazoan B-type cyclins, these metazoan species also have distinct A- and B3-type genes. (B) The putative amino acid sequence of Drosophila Cyclin B3 is shown and compared to cyclin B3 from chicken (Gallant and Nigg 1994) and C. elegans (Kreutzer et al. 1995). Positions with identical amino acids in all three sequences are indicated by an asterisk bel ow the sequences. Positions with identical amino acids as in Drosophila Cyclin B3 are indicated by boldface print. Potential cyclin B3 signature sequences conserved in all B3-type cyclins and distinct from A- and B-type cyclins are boxed. Gaps are indicated by dashes.

\section{Results}

Cyclin B3 expression is correlated with mitotic proliferation

Our previous searches for Drosophila cyclins with PCR and low stringency hybridization had revealed single Cyclin A and Cyclin B genes in Drosophila (Lehner and O'Farrell 1990). While arguing against the presence of closely related A- and B-type pairs in Drosophila (as A 1/ $A 2$ or B1/B2 in vertebrates) these results did not rule out the existence of more distantly related cyclin genes like Cycl in B3. In fact, with a different pai $r$ of cyclin primers, we amplified a novel B3-like cyclin fragment. The amino acid sequence (Fig. 1B) predicted by a Drosophila Cyclin B3 CDNA was most closely related to cyclin B3 from chicken, C. elegans, and leech (GenBank accession no. U 55259) (Fig. 1A,B). Except for the destruction box, simiIarities were restricted to the cyclin box where the B3 types share between $39 \%$ and $46 \%$ identity.

We analyzed the expression of Drosophila Cyclin B3 during development. On N orthern blots, we observed a major 2.7-kb band and an additional minor 3.1-kb band that was apparent only in early embryos and females (not shown). In situ hybridization experiments demonstrated that Cyclin B3 is expressed in mitotically proliferating cells. The maternally derived mRNA present during the early syncytial cycles 1-13 (Fig. 2A) appears to be exhausted by the stage of full germ-band extension, as suggested by in situ hybridization with embryos homozygous for the deficiency Df(3R)XTA1 (Fig. 2D), which deletes Cyclin B3. In addition, it also deletes the tolloid gene required for normal gastrulation. Therefore, Cyclin
B3-deficient embryos could be identified based on the abnormal morphology reflecting tolloid loss. The comparison of in situ hybridization signals in Cyclin B3-deficient and si bling embryos indicated that zygotic Cyclin B3 expression started during cellularization (data not shown). Although Cyclin B3 mRN A was detected in all mitotically proliferating cells, signals were particularly prominent in neuroblasts (Fig. 2C,I). In postmitotic and endoreduplicating cells of late embryos, we no longer observed signals above background (Fig. 2J,K). A part from the rel ative abundance in neuroblasts, the observed distribution of Cyclin B3 transcripts during embryogenesis is identical as previously described in the case of Cyclin A and Cyclin B (Lehner and O'Farrell 1990), and distinct from Cyclin E, which is also expressed in endoreduplicating cells (Richardson et al. 1993; Knoblich et al. 1994).

Zygotic transcription of Cyclins A, B, and B3 precedes germ cell proliferation in embryonic gonads

As described previously (Whitfield et al. 1989; Lehner and O'Farrell 1990; Raff et al. 1990; Dalby and Glover 1992, 1993), maternally provided Cyclin B mRN A is concentrated preferentially at the posterior end of the freshly laid egg and is incorporated into the pole cells when these germ-line progenitors form at the posterior pole (Fig. 2E,F). In addition, nonlocalized maternal Cyclin B transcripts migrate in association with the microtubules surrounding the syncytial nuclei to the egg periphery during nuclear migration and are apically localized during and after cellularization (Fig. 2E). In contrast, 


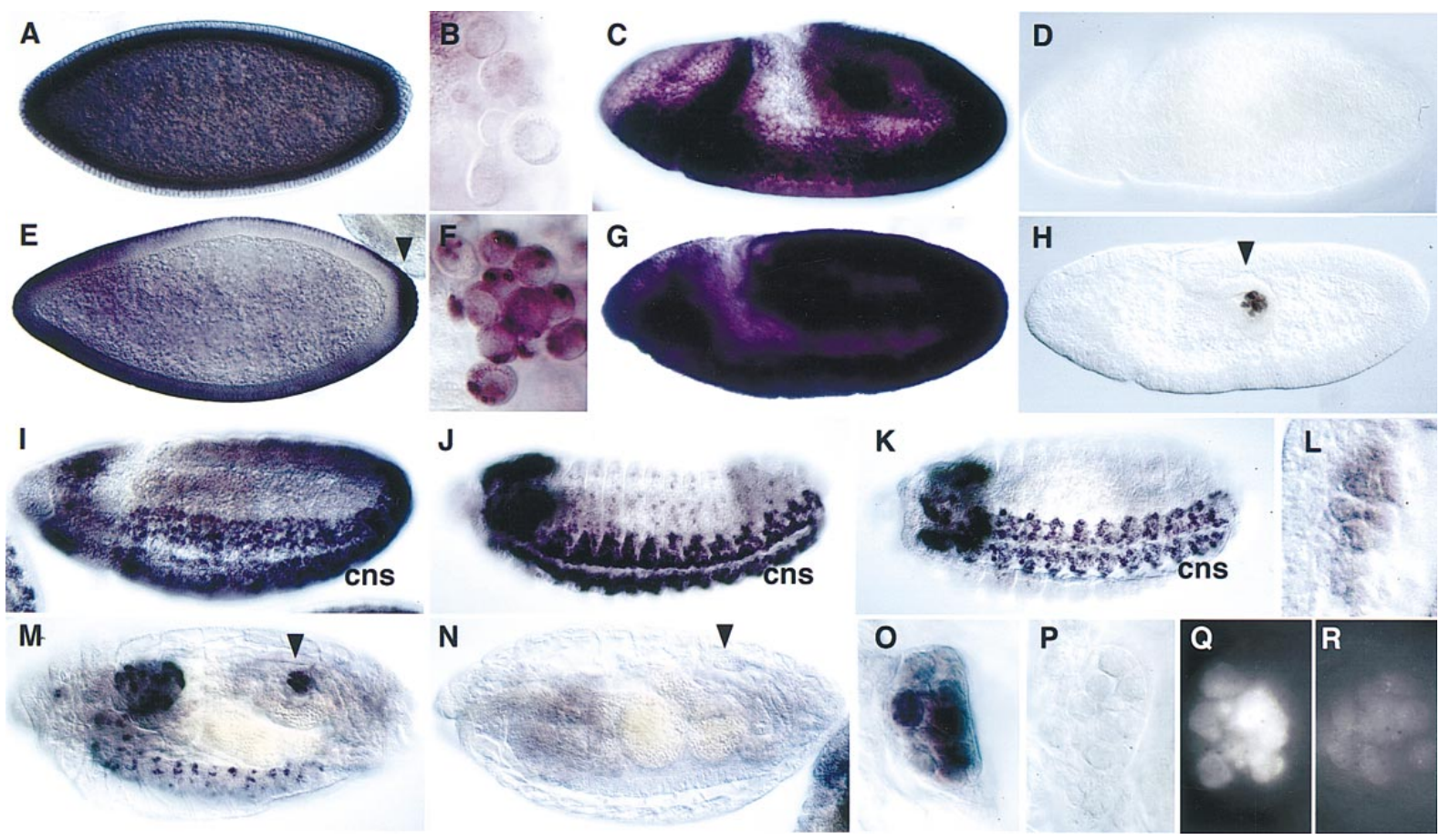

Figure 2. Cyclin B and Cyclin B3 expression in germ line and soma during embryogenesis. The distribution of Cyclin B3 mRNA $(A-D, I-L)$ was analyzed and compared to Cyclin B mRN A (E-H,M-P) by in situ hybridization using wild-type embryos (A-C,E-G,I$M, O)$, Cyclin B3-deficient Df(3R)XTA 1 embryos (D) and Cyclin B-deficient Df(2R)59AB embryos ( $H, N, P)$ at stage 5 (A,E), in pole cells at stage $6(B, F)$, at stage 8 during germ-band extension $(C, D, G, H)$, at stage $10(I), 13(J), 14(K, L)$, and $16(M-P)$. L, O, and P show embryonic gonads at high magnification at the stages shown in $\mathrm{K}, \mathrm{M}$, and $\mathrm{N}$, respectively. Immunofluorescent labeling with an antibody against Cyclin B $(Q, R)$ was used to detect accumulation of Cyclin B protein in embryonic gonads of Cyclin B-deficient Df(2R)59A B embryos (R) and Cyclin B ${ }^{+}$sibling embryos (Q) at stage 14. Arrowheads indicate pole cells. (cns) Central nervous system. (For further explanation, see text.)

maternal Cyclin B3 transcripts behaved like Cyclin A transcripts (Whitfield et al. 1989; Lehner and O'Farrell 1990; Raff et al. 1990). They were not concentrated in pole cells and were found on the basal side of the nuclear layer during cellularization (Fig. 2A,B).

The localized Cyclin B mRNA in pole cells has been suggested to become translationally activated when the germ-line progenitors resume cell proliferation after gonad formation during late embryogenesis ( $D$ alby and Glover 1993). This preferential partitioning of maternal Cyclin B transcripts into pole cells in combination with translational activation of the initially inactive mRNA at stage 14, has been proposed to provide Cyclin B for resumption of late embryonic germ-line proliferation, as zygotic Cyclin B transcription was not detected in the gonad at this stage (Dal by and Glover 1993).

Because maternal Cyclin B3 and Cyclin A transcripts are not enriched in polecells, we anal yzed whether these genes are activated transcriptionally in gonads before resumption of late embryonic germ cell proliferation. Beginning at stage 14 , specific signal s started to reappear in germ cell progenitors after in situ hybridization (Fig. 2L; data not shown). M oreover, we al so detected zygotic Cyclin B transcription in germ-line progenitors after gonad formation (Fig. 2M,O). Although germ-line progenitors were clearly label ed in control embryos with a Cyclin B gene (Fig. 2M ,O), we observed only background levels in Cyclin B-deficient sibling embryos (Fig. $2 \mathrm{~N}, \mathrm{P}$ ), which develop even beyond stage 14 without obvious defects (Knoblich and Lehner 1993). The maternal Cyclin B transcripts, which are readily detected at earlier embryonic stages in Cyclin B-deficient embryos (Fig. 2H), therefore, do not perdure until germ cell proliferation resumes. M oreover, anti-Cyclin B immunolabeling signals started to increase during stage 14 in gonads of control embryos, but not in Cyclin B-deficient sibling embryos (Fig. 2, cf. $\mathrm{Q}$ with $\mathrm{R}$ ). If the late embryonic $\mathrm{Cyclin} B$ accumulation in the gonads was exclusively from translation of maternal mRN A, as proposed (Dal by and Glover 1993), immunofluorescent labeling intensities would be expected to be independent of the zygotic genotype. Our discordant results demonstrate that Cycl in B expression at stage 14 does not reflect translational activation of maternal transcripts. Cyclin B is activated transcriptionally preceding the resumption of germ-line proliferation just like Cyclin A and Cyclin B3.

Cyclin B3 accumulates in the cell nucleus and binds to $\mathrm{Cdk} 1(\mathrm{Cdc} 2)$

Immunofluorescence labeling further confirmed the correlation between Cyclin B3 expression and mitotic pro- 
liferation (Fig. 3A,C). M oreover, double labeling experiments to compare the presence of Cyclin B3 with that of Cyclin A or Cyclin B did not reveal differences (data not shown). The specificity of the immunolabeling was controlled in experiments with the deficiency Df(3R)XTA 1. In these experiments, we anal yzed homozygous deficient embryos carrying a tolloid ${ }^{+}$transgene (Shimell et al . 1991), which rescued the gastrulation defects. As previously shown for Cyclin B-deficient embryos (Knoblich and Lehner 1993), we al so did not detect obvious developmental defects in these Cyclin B3-deficient tolloid ${ }^{+}$; Df(3R)XTA 1 embryos (see bel ow). A ccompanying the exhaustion of the maternal Cyclin B3 mRN A in these embryos, Cyclin B3 accumulati on reached lower level s with every cell cycle. Although remaining slightly above background before the fifteenth round of mitosis, immunofluorescent signals were no longer significant before mitosis 16 (Fig. 3B; data not shown).

Immunofluorescent labeling al so suggested a discrete subcellular localization and mitotic degradation of CycIin B3. Cyclin B3 accumulated in the nucleus during interphase. During mitosis, labeling was found to be very intense early in prophase (Fig. 3D-F, arrowhead p), became progressively distributed throughout the cell until metaphase (Fig. 3D-F, arrowhead m), and disappeared
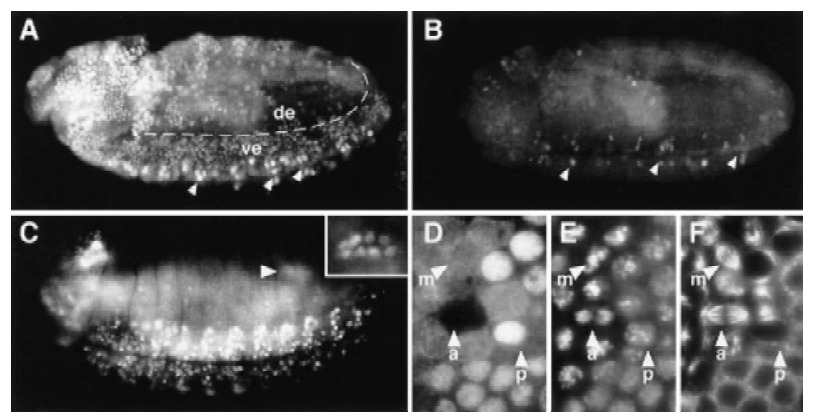

Figure 3. Cyclin B3 protein distribution during embryogenesis and cell cycle progression. Wild-type embryos (A,C-F) or Cyclin B3-deficient $\mathrm{P}\left[\mathrm{w}^{+}\right.$, tolloid $\left.{ }^{+}\right]$; Df(3R)XTA1 embryos (B) were stained by immunofluorescence using an antibody against $C y$ clin B3 (A-D) and double labeled with a DNA stain (E) and anti-tubulin antibodies (F). The embryos shown are at stages 10 $(A, B)$ and 14 (C). Cyclin B3 immunolabeling reflects the embryonic division program in wild-type embryos (A). The most intensely stained cells al ong the ventral midline (arrowheads) are still in $\mathrm{G}_{2}$ phase of cycle $14\left(\mathrm{G}_{14}\right)$. Ventral epidermal cells (ve) are in $G_{2}$ of cycle 15 and have less signal. Dorsolateral epidermal cells (de) have just progressed through mitosis 15 and have not yet reaccumulated Cyclin B3. Cyclin B3 immunolabeling in Cyclin B3-deficient embryos (B) illustrate the exhaustion of the maternal Cyclin B3 contribution. $\mathrm{G}_{14}$ cells al ong the ventral midline (arrowheads) have al ready less signal in Cyclin B3-deficient (B) compared to wild-type embryos (A). All the other cells that have progressed through mitosis 14 in the Cyclin B3-deficient embryo (B) no longer accumulate Cyclin B3 to clearly detectable levels. The region of the pole cells (arrowhead in $C$ ) is shown in focus at higher magnification in the inset. (D-F) A region with cells progressing through mitosis 14 . Selected cells in prophase (arrowhead p), metaphase (arrowhead $\mathrm{m})$, and anaphase (arrowhead a) are indicated. during anaphase (Fig. 3D-F, arrowhead a). Anti-Cyclin B3 labeling was absent from telophase and early interphase cells (Fig. 3A).

Immunoblotting experiments with extracts from embryos in which a synchronous progression through mitosis 14 had been enforced confirmed that Cyclin B3 is degraded during mitosis. Although an additional band with lower mobility appeared during prophase, immunobl ot signals decreased strongly during anaphase and telophase (Fig. 4A).

Coimmunoprecipitation experiments with embryo extracts were used to analyze cdk partners of Cyclin B3. Whereas we observed coimmunoprecipitation of Cyclin $\mathrm{B} 3$ and $\mathrm{Cdk} 1$, we could not detect coimmunoprecipitation of Cyclin B3 and Cdk2 (Fig. 4B). Immunoprecipitates obtained with the antibodies against $\mathrm{Cycl}$ in $\mathrm{B} 3$ contained histone $\mathrm{H} 1$ kinase activity (Fig. 4B,C), but only when isolated from embryos with a Cyclin $B 3$ gene and not from Cyclin B3-deficient sibling embryos (Fig. 4C).

Cyclin B and Cyclin B3 are not essential for viability but required for fertility

The identification of P-element insertions (Fig. 5) in Cyclin B and Cyclin B3 (in the following designated as $\mathrm{CycB}^{1}$ and $\mathrm{CycB} 3^{1}$, respectively) allowed a genetic characterization. $\mathrm{CycB3}^{1}$ abolished expression as suggested by immunolabeling (data not shown). However, neither of these two insertions was associated with recessive lethality. By mobilizing the insertions, we isolated chromosomes with small deletions resulting from imprecise excisions $\left(\mathrm{CycB}^{2}, \mathrm{CycB}^{3}, \mathrm{CycB3}^{2}\right.$, and $\left.\mathrm{CycB3^{3 }}\right)$. These small deletions included the region encoding $\alpha$-helix 1 , a conserved element of the cyclin box essential for cdk binding (Kobayashi et al. 1992; Jeffrey et al. 1995). Homozygous and hemizygous carriers of these null alleles reached adulthood demonstrating that neither $C y c l$ in $B$ nor Cyclin B3 is essential for viability. Mitosis, there fore, can proceed without either Cyclin B or Cyclin B3.

Both genes, however, are required for fertility. Sterility in both sexes was observed in mutants lacking completely Cyclin B function. Cyclin B mutant females had rudimentary ovaries and laid very few eggs. A Cyclin B transgene restored fertility in these Cyclin B null mutants. In Cyclin B3 null mutants, sterility was only observed in females and was also restored by a Cyclin B3 transgene. The Cyclin B3 mutant females had normal ovari es and oogenesi s appeared to proceed normally until after entry into meiosis I, whereas exit from meiosis after egg activation was defective.

\section{Cyclins A, B, and B3 cooperate during mitosis}

Previously we have observed that Cyclin A and Cyclin B are partially redundant (Knoblich and Lehner 1993). We suspected that redundancies might also explain the surprising result that Cyclin B and Cyclin B3 are not essential for viability. In contrast to single mutants, double mutants homozygous for null alleles of both Cyclin B 


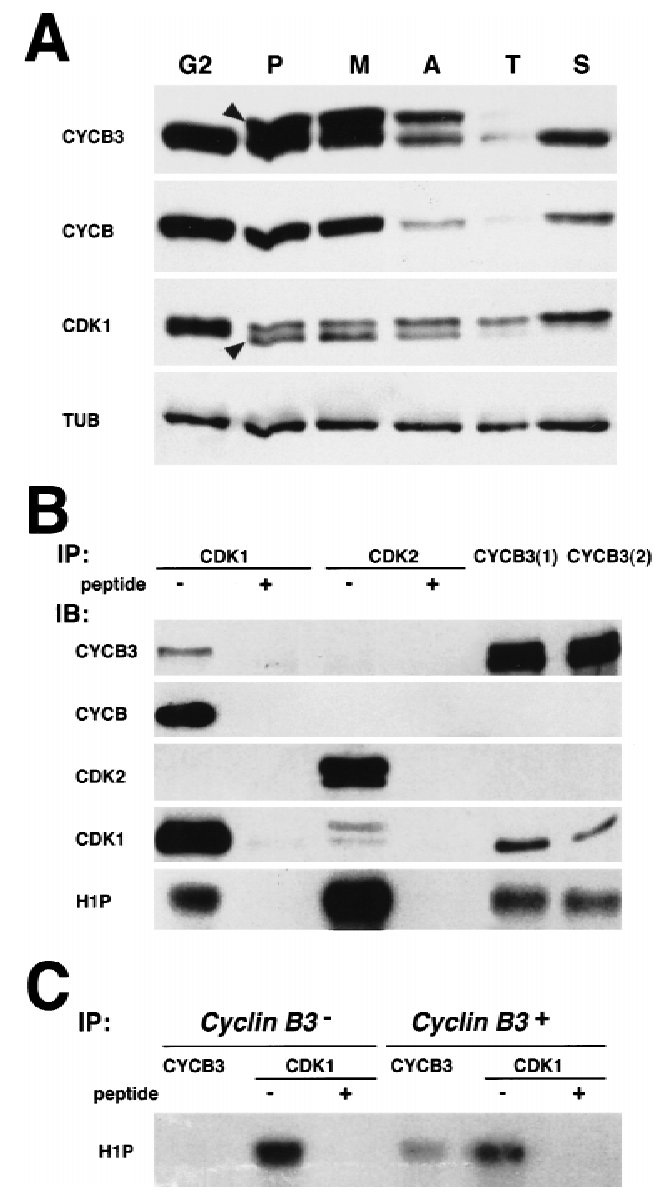

Figure 4. Cyclin $B 3$ associates with $\mathrm{Cdk} 1(\mathrm{Cdc} 2)$ and is degraded during mitosis. (A) Cells were forced through mitosis 14 synchronously (see Materials and M ethods) and embryos with all cells during $G_{2}$ before mitosis $14(G 2)$, during prophase (P), metaphase $(M)$, anaphase $(A)$, and telophase $(T)$ of mitosis 14 , and early in the next S phase (S) were selected microscopically after fixation and pooled for extract preparation. Extracts were analyzed by immunoblotting with antibodies against $\mathrm{Cyclin} B 3$ (CYCB3), Cyclin B (CYCB), Cdk1 (CDK1), and tubulin (TUB). Arrowheads indicate bands with altered mobility appearing in prophase. (B) Association of Cyclin B3 with Cdk1 and Cdk2 was analyzed by coimmunoprecipitation from 2- to 4-hr embryo extracts. Two affinity-purified antibodies against Cyclin B3 [CYCB3(1) and CYCB3(2)] as well as antibodies against a carboxy-terminal peptide of Cdk1 (CDK1) or Cdk2 (CDK2) were used for immunopreci pitation (IP) in the absence $(-)$ or presence $(+)$ of competing peptide. The immunoprecipitates were analyzed either by immunobl otting (IB) with antibodies against $\mathrm{Cy}$ clin B3 (CYCB3), Cyclin B (CYCB), Cdk2 (CDK2), Cdk1 (CDK1), or in histone $\mathrm{H} 1$ kinase assays (H IP). (C) Immunopreci pitations from either Cyclin B3-deficient Df(3R)XTA1 embryo extracts (Cyclin B3-) or hemizygous sibling embryo extracts (Cyclin $\left.\mathrm{B}^{+}{ }^{+}\right)$ with anti-Cyclin B3 (CYCB3) or anti-Cdk1 (CDK1) antibodies in the absence $(-)$ or presence $(+)$ of competing peptide were analyzed by histone $\mathrm{H} 1$ kinase assays.

and Cyclin B3 did not reach adulthood except after introduction of either a Cyclin $\mathrm{B}^{+}$or a Cyclin $\mathrm{B}^{+}$transgene into the double mutant background. We analyzed progression through the embryonic division program in double mutants using anti-tubulin/DN A labeling to visualize mitosis and BrdU labeling to monitor S phase. The first 14 mitoses still occurred normally in $~ 60 \%$ of the embryos presumably because of the maternal Cyclin B and Cyclin B3 contributions deposited in the egg during oogenesis in the double heterozygous mothers. However, $40 \%$ of the progeny devel oped abnormally during the syncytial stages irrespective of the zygotic genotype. N uclear density in these embryos was often highly variable in different regions of the egg. Double heterozygosity for Cyclin B and Cyclin B3 null mutations, therefore, presumably results in a reduced maternal contribution that in many embryos is no longer sufficient for a normal progression through the rapid syncytial cycles.

Although Cyclin B3- (Fig. 6A,B) or Cyclin $\mathrm{B}^{-}$(Fig. $6 C, D)$ single mutants still progressed normally through mitosis 15, all Cyclin $\mathrm{B}^{-}$Cyclin $\mathrm{B3}^{-}$double mutants were abnormal during mitosis 15 (Fig. 6E,F,I-L) even before the maternal contributions became completely undetectable (see Fig. 3B; Knoblich and Lehner 1993). Entry into mitosis 15 was del ayed in these double mutants and progression through mitosis was slow as evidenced by the distribution of mitotic figures. As illustrated in Figure $3 \mathrm{~A}$, mitosis 15 begins in the dorsolateral region and occurs later in the ventral region during wild-type embryogenesis. Double mutants had no mitotic figures in the ventral region at stages where mitosis had al ready progressed into the ventral region of sibling embryos (Fig. 6, cf. C and E). Inspection at higher magnification revealed an enrichment of prophase figures in double mutants (Fig. 6, cf. F with B and D, prophases indicated by arrowheads). Double labeling with a DNA stain indicated that chromatin condensation had started in these prophase cells (Fig. $6 \mathrm{l}, \mathrm{J}$ ). The great majority of metaphase, anaphase, and tel ophase figures were abnormal in double mutants at the stage of mitosis 15. Metaphase

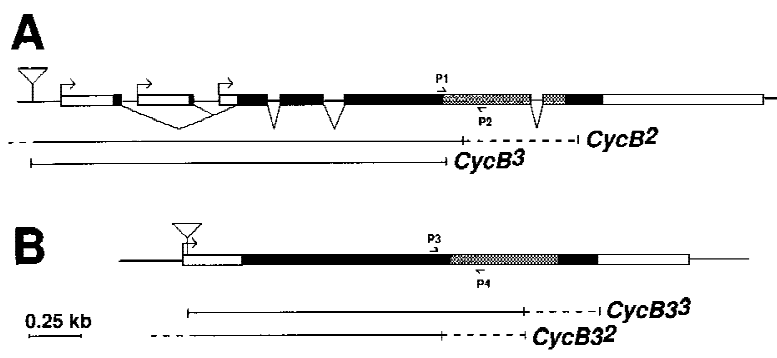

Figure 5. Isolation and characterization of null mutations in Cyclin B and Cyclin B3. Schematic drawings illustrating transcribed regions (boxed), coding regions (black filling), P-element insertion sites (triangles), and the deletions associated with imprecise excisions of the P-el ement insertions in Cyclin B (A) and Cyclin B3 (B). In the case of Cyclin B, the existence of multiple transcriptional start sites is suggested by different CDNA sequences. The deletions were analyzed by PCR using various primers including those indicated by arrows $\mathrm{P} 1$ to $\mathrm{P} 4$, which hybridize to sequences flanking the region encoding the conserved $\alpha$-helix 1 (Jeffrey et al. 1995) of the cyclin box (hatched filling). Solid lines indicate del eted sequences. Breakpoints were mapped to the regions indicated by broken lines. 


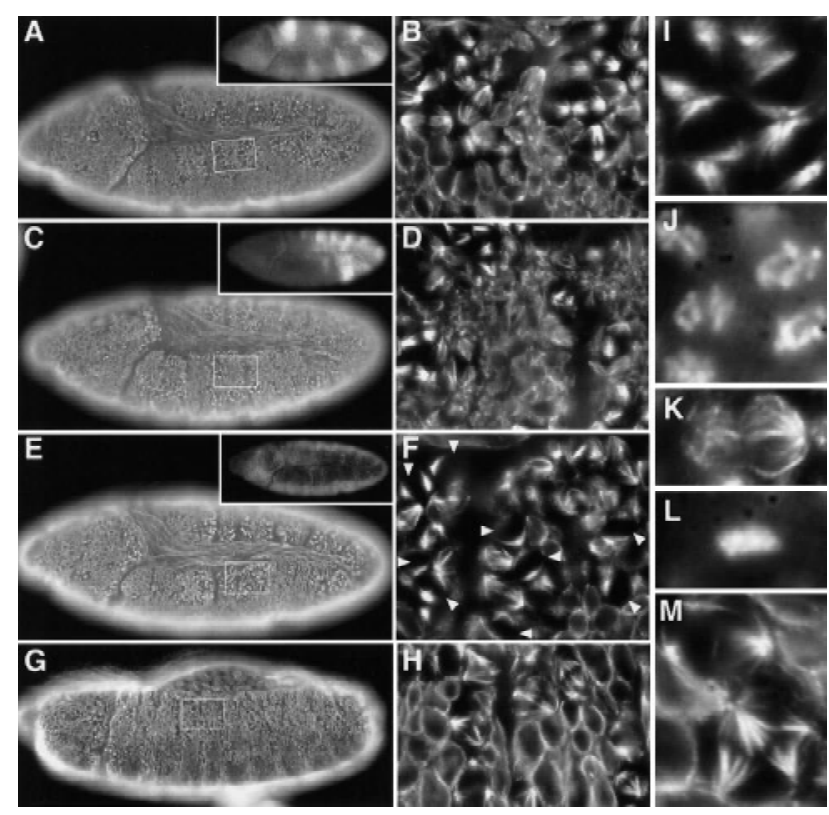

Figure 6. Cyclin B and Cyclin B3 cooperate during mitosis. Eggs from Df(2R)599-5/CyO, P[w ${ }^{+}$, ftz-lacZ]; CycB3 ${ }^{1} / \mathrm{TM}$, $\mathrm{P}\left[\mathrm{w}^{+}, \mathrm{U} \mathrm{bx}-\mathrm{lac} Z\right]$ flies were collected and aged to stage $10(\mathrm{~A}-\mathrm{F})$ or stage $13(\mathrm{G}, \mathrm{H})$ followed by fixation and immunofluorescent labeling with antibodies against $\beta$-galactosidase for genotype determination (insets), against tubulin (A-I,K,M), and a DNA stain (J,L). Df(2R)599-5 deletes Cyclin B. The P[w ${ }^{+}$, lacZ] enhancer trap insertion in the $\mathrm{CycB}^{1}$ allele results in $\beta$-galactosidase expression reflecting the Cyclin B3 expression pattern. Indistinguishable phenotypes were also obtained with the $\mathrm{CycB}^{2}$ and $\mathrm{CycB}^{3}$ null alleles (not shown). (A,B) Cyclin B3 ${ }^{-}$ embryo; (C,D) Cyclin $B^{-}$embryo; $(E-M)$ Cyclin $B^{-}$Cyclin B3 ${ }^{-}$ double mutant embryos. Boxed regions from the epidermis of the embryos shown in A, C, E, and G are shown at higher magnification in $B, D, F$, and $H$, respectively. Even higher magnifications illustrate the enrichment of prophase figures $(I, J)$, the presence of defective late mitotic figures $(\mathrm{K}, \mathrm{L})$ during mitosis 15 at stage 10, and multipolar spindles at stage 13 in Cyclin $\mathrm{B}^{-}$ Cyclin $\mathrm{B}^{-}$double mutants (M). For further explanations see text.

spindles were often kinked and sister chromatid separation appeared delayed rel ative to cytokinesis. Although sister chromatids are al ways at the poles when cytokinesis starts in wild-type cells (Lehner 1992), we often observed unseparated decondensing chromatin in the equator of cells in double mutants that had already started cytokinesis (Fig. 6K,L).

Although many cells failed to complete cell division successfully, they eventually left mitosis 15 and entered into S phase 16. Double mutants displayed no mitotic figures and still incorporated BrdU at the stage where mitosis 16 occurred in sibling embryos (not shown). However, many mitotic figures were again present later in double mutants at the end of germ-band retraction (Fig. 6G,H). The spindles in these mitotic cells were often tetrapolar (Fig. 6M ). In wild-type embryogenesis, al I epidermal cells are al ready postmitotic at this stage and mitotic figures were no longer detectable (e.g., see Fig. 7E,F).
All our observations indicate that mitosis 15 is delayed, slow, and often not successful in Cyclin $\mathrm{B}^{-}$Cyclin B3 $^{-}$double mutants. When cells eventually exit from mitosis 15 in these mutants, they still enter into the subsequent $\mathrm{S}$ phase 16 . This delayed $\mathrm{S}$ phase might contribute by a checkpoint mechanism to a further delay of entry into mitosis 16 . The tetrapolar spindles observed during this very late mitosis 16 presumably reflect a failure to divide successfully in the previous mitosis 15. Because mitosis 15 and 16 are severely affected in double but not in single mutants, and because S phase 15 and 16 , as well as endoreduplication during late embryogenesis still occurs (data not shown, but see below), we conclude that Cyclin B3 cooperates with Cyclin B and that it is important specifically for mitosis.

We also analyzed the embryonic division program in Cyclin $\mathrm{A}^{-}$Cyclin $\mathrm{B3}^{-}$double mutants. Cyclin $\mathrm{A}^{-}$single mutants progress normally through mitosis 15 (Lehner and O'Farrell 1989) like Cyclin $\mathrm{B}^{-}$single mutants.

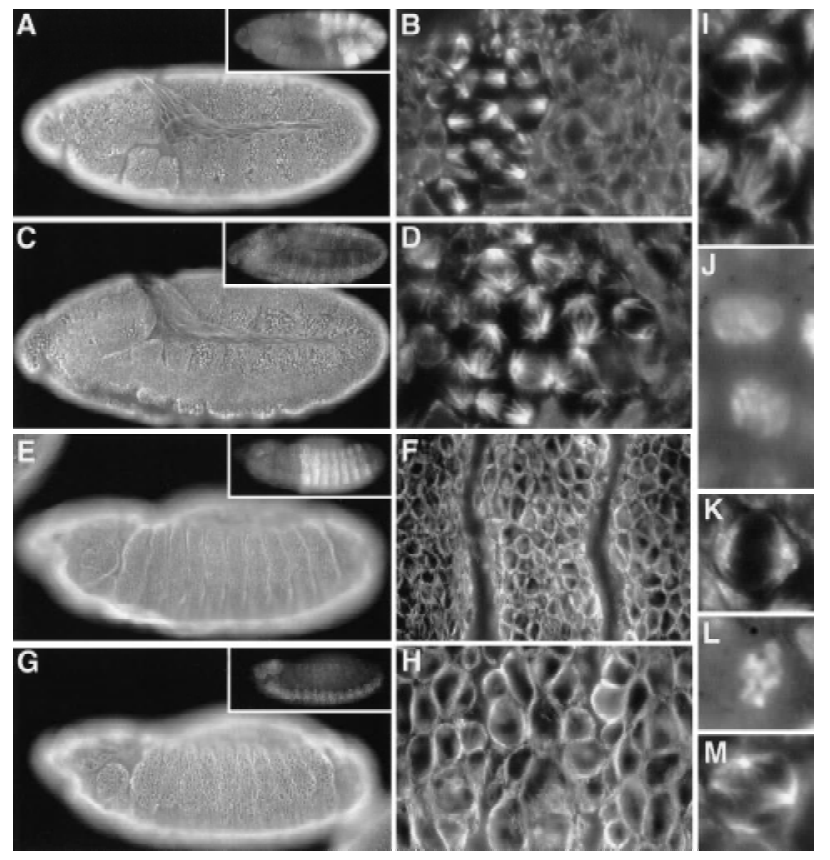

Figure 7. Cyclin $A$ and $C y c l i n ~ B 3$ cooperate during mitosis. Eggs from CyCA ${ }^{\mathrm{C} 8 \mathrm{LR} 1} \mathrm{CyCB}^{1} / \mathrm{TM} 3, \mathrm{P}\left[\mathrm{w}^{+}, \mathrm{U}\right.$ bx-lacZ flies were collected and aged to stage $11(A-D, I-L)$ or stage $13(E-H, M)$ followed by fixation and immunofluorescent labeling with antibodies against $\beta$-gal actosi dase for genotype determination (insets), against tubulin (A-I,K,M), and a DN A stain (J,L). The P[ $\left[\mathrm{w}^{+}\right.$, lacZ] enhancer trap insertion in the $\mathrm{CycB}^{1}$ allele results in $\beta$-galactosidase expression reflecting the $C y c l i n$ B3 expression pattern. (A,B,E,F,K,L) TM3, P[w $\left.{ }^{+}, \mathrm{Ubx}-\mathrm{lacZ}\right]$ embryos that served as internal controls; $(C, D, G-J, M)$ Cyclin $A^{-}$Cyclin $B^{-}$ double mutant embryos. Regions from the epidermis of the embryos shown in A, C, E, and G are shown at higher magnification in $B, D, F$, and $H$, respectively. Even higher magnifications illustrate del ayed chromatin condensation during prophase during mitosis 15 at stage 10 (cf. I and J with $\mathrm{K}$ and L), and rare mitotic cells with aberrant multipolar spindles at stage 13 in Cyclin $\mathrm{A}^{-}$Cyclin $\mathrm{B3}^{-}$double mutants (M). For further explanations, see text. 
However, double mutants entered mitosis 15 with an even more pronounced delay than in Cyclin $\mathrm{B}^{-}$Cyclin $\mathrm{B}^{-}$-doubl e mutants. At the stage where mitosis 15 eventually occurred in Cycl in $\mathrm{A}^{-}$Cyclin $\mathrm{B}^{-}$double mutants, sibling embryos were al ready in mitosis 16 (Fig. 7, cf. A,B with $C, D$ ). Although spindle assembly after entry into mitosi s appeared to be relativel y normal, chromatin condensation appeared to be slow in double mutants. Cells with prophase-like spindles in double mutants had chromatin that appeared to be less condensed than in sibling control embryos (Fig. 7, cf. I and J with $\mathrm{K}$ and L). As described above for $\mathrm{Cyclin} \mathrm{B}^{-}$Cyclin $\mathrm{B3}^{-}$double mutants, after a delay some cells eventually left $M$ phase often despite division failure, and entered into $\mathrm{S}$ phase of cycle 16 (data not shown). However, reentry into mitosis 16 no longer occurred, in line with the phenotype of Cyclin $A^{-}$single mutants (Lehner and O'Farrell 1989). The frequency of mitotic figures decreased continuously during germ-band extension in Cyclin $\mathrm{A}^{-}$Cyclin $\mathrm{B3}^{-}$ double mutants. At the end of germ-band extension, mitotic figures were very rare, abnormal, and often multipolar (Fig. 7G,H,M ). Because S phase 15 appeared normal in these double mutants (data not shown, but see below) and because the first defects are evident during the subsequent mitosis 15 , which is normal in single mutants, we conclude that Cyclin B3 al so cooperates with Cyclin A for progression through mitosis.

Finally, we analyzed the embryonic division program in Cyclin $\mathrm{A}^{-}$, Cyclin $\mathrm{B}^{-}$, Cyclin $\mathrm{B}^{-}$triple mutants. AIthough a large fraction of the progeny of triple heterozygous mothers were again highly abnormal al ready during the syncytial stages, $\sim 50 \%$ of the embryos still completed the syncytial cycles without obvious defects. The triple mutants that were not affected by maternal effect abnormalities were found to progress through mitosis 14 normally (data not shown). M oreover, BrdU Iabeling during the subsequent $S$ phase 15 also did not reveal defects in triple mutant embryos (Fig. 8, cf. A with B). However, mitosis 15 was blocked in triple mutant embryos (data not shown), as previously found in Cyclin $A^{-}$Cyclin $B^{-}$ double mutant embryos (Knoblich and Lehner 1993). Triple mutants failed to incorporate BrdU at the stage of the subsequent S phase 16, except for very rare cell pairs that presumably represent daughters of exceptional cells that had escaped the block of mitosis 15 (Fig. 8D). In addition, during subsequent embryonic development, we no longer observed BrdU incorporation in the CNS, which is known to proliferate mitotically in wild-type development. However, we still observed BrdU incorporation in late triple mutant embryos in tissues that are known to endoreduplicate in wild-type embryogenesis (Fig. 8, cf. E with F).

\section{Discussion}

Cyclin B3 is present in metazoan species in addition to the well-known A- and B-type cyclins. A cyclin B3 homolog cannot be recognized in the genome of Saccharomyces cerevisiae, that contains six B- and no A-type cyclin genes. In addition, B3 types have not yet been iden-
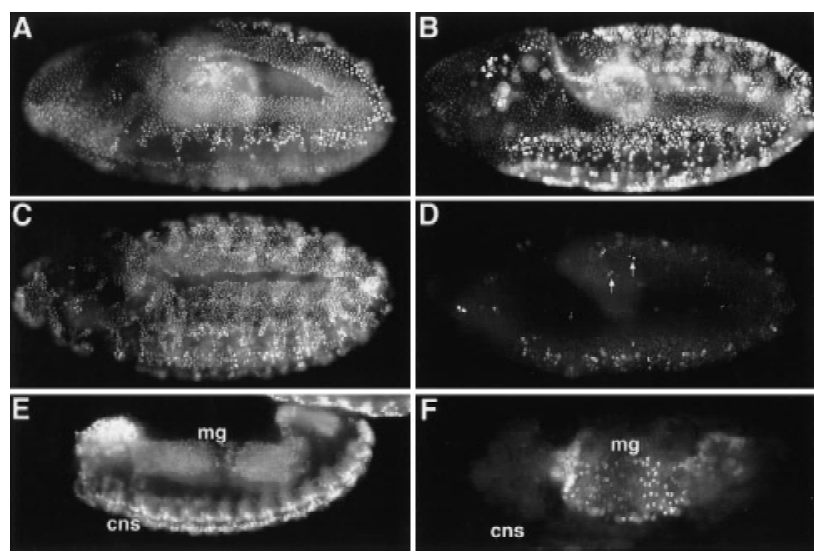

Figure 8. DN A replication in mitotic cyclin mutants. Embryos at the appropriate devel opmental stages were pul se label ed with BrdU followed by double labeling with anti-BrdU antibodies $(\mathrm{A}-\mathrm{F})$ and anti- $\beta$-gal actosidase antibodies for genotype determination (not shown). Control embryos are shown in A, C, E and Cyclin $\mathrm{A}^{-}$Cyclin $\mathrm{B}^{-}$Cyclin $\mathrm{B}^{-}$triple mutants (Df(2R)59AB; $\left.\mathrm{CyCA}^{\mathrm{C}{ }^{8 L R 1} \mathrm{CyCB}^{1}}{ }^{1}\right)$ in B, D, F. (A,B) stage 9; $(C, D)$ stage 10; $(E, F)$ stage 14. Arrows in $D$ indicate rare pairs of BrdU-positive nuclei in the epidermis of triple mutants at the stage of S phase 16. (cns) Central nervous system; (mg) midgut. For further explanations, see text.

tified in plants, which appear to have both A- and B-type cyclins. However, cyclin B3 has been described in chicken (Gallant and N igg 1994), C. elegans (Kreutzer et al. 1995), leech, and Drosophila melanogaster (Sigrist et al. 1995; this study). These metazoan B3-type cyclins are clearly distinct from both A- and B-type cyclins (Fig. 1).

The classification into A-, B-, and B3-type cyclins is based on structural comparisons. To address functional differences between Cyclin B3 and Cyclins A and B, we have compared the developmental expression patterns, the subcellular local izati on during the cell cycle, and the cdk partners in Drosophila embryos. In addition, we have identified mutations in mitotic cyclin genes. Our phenotypi c comparisons of single, double, and triple mutants demonstrate that $\mathrm{Cyclin} \mathrm{B} 3$ is involved in the regulation of mitosis where it cooperates with Cyclins A and $\mathrm{B}$.

\section{The pattern of Cyclin B3 expression}

During the syncytial cycles at the onset of Drosophila embryogenesis, Cyclins A, B, and B3 are transl ated from maternal transcripts deposited in the egg during oogenesis. Maternal Cyclin B transcripts display an interesting localization. In contrast to maternal Cyclin A and B3 transcripts, which are uniformly distributed throughout the egg, these transcripts are enriched at the posterior pole where the germ-line progenitors form (Whitfiel d et al. 1989; Lehner and O'Farrell 1990; Raff et al. 1990; Dalby and Glover 1992, 1993). This localized maternal Cyclin B mRN A is incorporated into the germ-line progenitors where it has been suggested to be repressed translationally until after gonads have formed during 
mid-embryogenesis. Translational activation of this localized maternal mRNA has been proposed to provide Cyclin B protein for the late embryonic germ-line proliferation in the absence of zygotic Cyclin B transcription (Dal by and Glover 1993). Although our data do not address the issue of whether the maternal Cyclin B mRN A is subject to translational repression until gonad formation, we find that these maternal transcripts have largely decayed until cell proliferation resumes in the late embryonic gonads. M oreover, activation of zygotic Cycl in B expression is readily detectable before resumption of germ-line prol iferation. Therefore, the significance of the posterior enrichment of maternal Cyclin B mRNA remains to be clarified.

Cyclin B3 is present with Cyclins A and B in all mitotically proliferating cells. After the terminal division, when cells become postmitotic during a $G_{1}$ phase, we can no longer detect the accumulation of Cyclin B3 as previously described for the other mitotic cyclins. M oreover, we also cannot detect expression in endoreduplicating tissues suggesting that Drosophila Cyclin B3, like Cyclins A and B, does not have an essential role for DN A replication. This conclusion is further supported by our finding that BrdU is incorporated in endoreduplicating tissues in all single, double, and triple mutants.

\section{Cdk partners and nuclear localization of Cyclin B3}

Chicken Cyclin B3 is capable of binding equally well to both cdk1 and cdk2 after expression in HeLa cells (GalIant and Nigg 1994). In contrast, we cannot detect coimmunoprecipitation of Cyclin B3 and Cdk2, although we clearly observe Cyclin B3/Cdk1 complexes in Drosophila. The association of chicken cycl in B3 and human cdk2 might be artifactual, resulting from overexpression of a heterol ogous protein. We note, however, that vertebrate and Drosophila Cyclin A display the same difference in association specificity. Vertebrate cyclin A2 associates with both $\mathrm{cdk} 1$ and $\mathrm{cdk} 2$, whereas Drosophila Cyclin A is detected exclusively in Cdk 1 complexes in embryos (T sai et al. 1991; Knoblich et al. 1994; Howe et al. 1995). Therefore, cyclin B3/cdk2 complexes might be present in vertebrates and involved in the control of $S$ phase, as already described for vertebrate cyclin A2. In Drosophila embryos, however, Cyclins A, B, and B3 are only observed in $\mathrm{Cdk} 1$ complexes and are not required for $\mathrm{S}$ phase, at least in endoreduplicating tissues.

Cyclin B3 has a very distinct subcellular Iocalization during interphase. Although Drosophila Cyclins $A$ and $B$ accumulate in the cytoplasm, Cyclin B3 accumulates in the cell nucleus, although it does not display $\mathrm{Cdk} 2$ binding, a critical determinant for nuclear localization of vertebrate cyclin A2 (Maridor et al. 1993). The cyclin B3 sequences from chicken, leech, and Drosophila contain a potential bipartite nuclear-targeting signal. These nuclear-targeting signals overlap with the putative destruction box in chicken (Gallant and Nigg 1994) and Drosophila.

The functional significance of the subcellular localization of Cyclin B3, as well as that of A- and B-type cyclins, is not understood, al though compl ex regulation has been described in some cases in particular during the $\mathrm{G}_{2} / \mathrm{M}$ transition (Lehner and O'Farrell 1989; Whitfield et al. 1990; Pines and Hunter 1991, 1994; Gallant and Nigg 1992; Jackman et al. 1995; Li et al. 1997). In addition, the subcellular localization of the kinases and phosphatases modifying and regulating $\mathrm{Cdk} 1$ when bound to mitotic cyclins is controversial (M illar et al. 1991; Heald et al. 1993; Baldin and Ducommun 1995; Mueller et al. 1995). Hence, we do not know when and where the different $\mathrm{Cdk} 1$ complexes are activated during the $\mathrm{G}_{2} / \mathrm{M}$ transition. The fact that cells can divide without Drosophila Cyclins B or B3 does not necessarily mean that the control of subcel lular localization is irrel evant, as their presence at the wrong location might be more harmful than their absence.

\section{Mitotic functions of Cyclin B and Cyclin B3}

Surprisingly, we found that Cyclins B and B3 are not essential for viability demonstrating that cell divisions can proceed without either Cyclin B or Cyclin B3. We did not detect mitotic abnormalities in Cyclin B3 mutant embryos. In the absence of Cyclin B, however, cell divisions are slower than in wild type. Mitotic figures are enriched and mitotic spindles are unusual in Cyclin B mutant embryos. Spindle fibers are not as strong and straight as in wild type. Cyclin B, therefore, appears to be required for an efficient reorganization of interphase microtubules into a mitotic spindle. Consistent with this notion, Cyclin B/Cdk1 is known to increase microtubule dynamics in vitro (Verde et al. 1990, 1992).

M utant embryos lacking both Cyclins B and B3 zygotically show much more severe mitotic defects than single mutants. Entry into mitosis is delayed. Mitotic spindle formation is severely disturbed as suggested by the drastic enrichment of prophase-like figures with condensed chromosomes and immature spindles. The spindles that are eventually formed appear to be largely incapable of segregating sister chromatids to the poles. The rare anaphase figures did not reveal the characteristic chromosome orientation indicative of the strong mechanical pull evident in wild-type anaphase, where chromosome arms trail behind leading centromeric regions on their way to the spindle poles. In addition to cooperation of Cyclins B and B3, we can also demonstrate synergy of Cyclins A and B3. Although chromatin condensation is particularly slow, spindle formation appears to be less affected in Cyclin $\mathrm{A}^{-}$Cyclin $\mathrm{B}^{-}$double mutants compared to $\mathrm{Cyclin} \mathrm{B}^{-} \mathrm{Cyclin} \mathrm{B3}^{-}$double mutants.

On the basis of our double mutant analyses (Knoblich and Lehner 1993; this study), we conclude that all of the mitotic cyclins cooperate to bring about progression through mitosis. Moreover, our results are consistent with the idea that Cyclin $A$ is most potent in triggering mitosis, whereas Cyclin B has an intermediate and Cyclin B3 the lowest potency. The results also confirm the suggestion that Cyclin B is particularly important for the organization of mitotic spindles. In addition, they suggest that Cyclin A, which translocates into the nucleus 
very early during prophase, and $\mathrm{Cyclin} \mathrm{B} 3$, which accumulates in the nucleus already during interphase, are particularly important for chromosome condensation.

Previously, we have proposed that different mitotic processes after the metaphase-anaphase transition might be temporally arranged by the ordered disappearance of Cyclins A, B, and B3 resulting from proteolytic degradation (Sigrist et al. 1995). Our proposal was based not only on this ordered disappearance of the different mitotic cyclins, but also on the specific mitotic defects resulting after the expression of mitotic cyclins with amino-terminal deletions, which also removed the destruction box. These mutant nondestructible Cyclins A, $B$, and $B 3$ were found to delay mitotic progression before sister chromatid separation, sister chromati d segregation to the poles, and telophase including cytokinesis, respectively (Sigrist et al. 1995). On the basis of our proposal, all these processes are expected to start simultaneously in Cyclin $\mathrm{B}^{-}$Cyclin $\mathrm{B}^{-}$double mutants after the disappearance of Cyclin A during mitosis. In fact, we observe that chromosome segregation to the poles, chromosome decondensation, and cytokinesis is attempted simultaneously in these double mutant embryos. However, the interpretation of these phenotypes is complicated by the fact that mitotic progression until metaphase is al ready severely affected and not just exit from mitosis. Moreover, we infer the temporal dynamics of the mitotic processes from our analysis of fixed samples based on the untested assumption that all cells are affected in the same way. Real-time analyses of cell divisions in living embryos should be feasible and might help to define the functional specialization of the different mitotic cyclins more precisely. Our results indicate, however, that mitotic cyclins are to some extent functionally overlapping. This functional overlap is less pronounced in the germ line and in particular during oogenesis where both Cyclin B and Cyclin B3 are essential. A future detailed characterization of the role of different mitotic cyclins in oogenesis, therefore, should be especially informative with regard to cyclin type-specific functions and regulatory differences between mitosis and mei osis.

\section{Materials and methods}

\section{Isolation of Cyclin B3 CDNA}

For the identification of Cyclin B3 we used a pair of degenerate primers for enzymatic amplification by PCR. The primer sequences were 5'-GCAGGATCCATGCGNGCNATNYTNRTNGAYTGG-3' and 5'-GCAGAATTCGGNGGRTADAWYTCYTCRWAYTT-3' introducing BamHI and EcoRI sites, respectively, at the ends. In the Drosophila Cyclin A gene these primers hybridize to the regions corresponding to amino acids 235-242 (MRSILIDW) and amino acids 291-298 (KYEEIYPP), respectively (Lehner and O'Farrell 1989). These regions are maximally conserved among the known A- and B-type cyclins. To facilitate the identification of novel cyclin genes and avoid the reisolation of Drosophila Cyclin $B$, we isolated genomic DN A from embryos homozygous for the deletion $D f(3 R) 59 A B$, which del etes the Cyclin B gene (Knoblich and Lehner 1993) and used this DN A as templatefor PCR. Cyclin B-deficient embryos were identified as described previously (Knoblich and Lehner 1993). A mplification was performed during 40 cycles ( $1 \mathrm{~min}$ at $94^{\circ} \mathrm{C}, 2 \mathrm{~min}$ at $50^{\circ} \mathrm{C}, 1 \mathrm{~min}$ at $72^{\circ} \mathrm{C}$ ) using Taq polymerase (Perkin-Elmer). PCR products were size-fractionated on agarose gels. Size fractionation provided sel ection against Cyclin A fragments as Cyclin A has a small intron in the corresponding region (Knoblich and Lehner 1993) resulting in a 260-bp PCR fragment. PCR products observed in the range of 210 bp were isolated, reamplified, and cloned into Bluescript $\mathrm{KS}(+)$ before sequence analysis. Although a number of clones contained sequences unrelated to cyclins, we found two classes of clones with cyclin-like sequences. The first class contained a Drosophila Cyclin E fragment (Richardson et al. 1993). The second class contained a novel cyclin-like sequence most closely related to the previously identified C. el egans Cyclin B3 (Kreutzer et al. 1995).

The Cyclin B3 PCR fragment was used as a probe for the isolation of cDNA clones from a library made from 0- to 4-hr Drosophila embryo poly(A)+ RNA (Brown and Kafatos 1988). Two positive clones with a $2.4-\mathrm{kb}$ and a $2.5-\mathrm{kb}$ cDNA insert, respectively, were purified and the longer CDN $A$ insert was sequenced completely (accession no. AJ006772). In addition, we al so isolated Cyclin B3 and Cyclin B genomic clones and determined genomic sequences (accession no. AJ006773).

Immunoblotting, immunoprecipitation, immunofluorescence, and in situ hybridizations

In situ hybridization to polytene chromosomes from larval salivary glands for the localization of the Cyclin B3 gene to the chromosomal region 96B2-6 was carried out with a digoxigeninlabeled CDN A fragment generated by random primer labeling. For the analysis of the distribution of transcripts in embryos, we also used digoxigenin-labeled Cyclin B (Lehner and O'Farrell 1990) and Cyclin B3 CDN A fragments for in situ hybridization.

For immunization of rabbits, full-length and an amino-terminal domain of Cyclin B3 (amino acids 1-245) as well as an amino-terminal domain of Cyclin B (amino acids 1-203) were expressed and purified from Escherichia coli. The resulting antisera were affinity purified.

Mouse monoclonal antibodies against Cyclin B and $\mathrm{Cdk} 2(\mathrm{Cdc} 2 \mathrm{c})$, and affinity-purified rabbit antibodies against carboxy-terminal peptides of either Drosophila Cdk1(Cdc2) or Cdk2(Cdc2c), have been described previously (Knoblich et al. 1994). To detect Cdk1(Cdc2) in immunoprecipitates, we used a mouse monoclonal antibody against the PSTAIR epitope ( $\mathrm{Ya}$ mashita et al. 1991) recognizing Drosophila Cdk1(Cdc2) with about hundredfold greater sensitivity than $\mathrm{Cdk} 2$ (Cdc2c) (Knoblich et al. 1994). Antibodies against $\beta$-tubulin (Amersham), digoxigenin (Boehringer $M$ annheim), $\beta$-galactosidase (Cappel), as well as all secondary antibodies were obtained commercially. Immunofluorescence, immunoblotting, immunoprecipitation experiments, and histone $\mathrm{Hl}$ kinase assays were performed as described previously (Knoblich et al. 1994).

For the preparation of extracts from Cyclin B3-deficient and sibling embryos, we collected eggs from Df(3R)XTA1/ Dp(3;3)SuM(3)w13 flies for $1 \mathrm{hr}$ and aged them for $6.5 \mathrm{hr}$ at $25^{\circ} \mathrm{C}$. After vitelline membrane removal, we sorted 200 homozygous Df(3R)XTA 1 embryos and 200 sibling embryos using a stereo microscope. Homozygous Df(3R)XTA1 embryos were identified based on the abnormal morphology resulting from the gastrulation defects. The two embryo fractions were used for extract preparation and immunoprecipitation.

Extracts from defined mitotic stages for immunoblot experiments were obtained as described by Sauer et al. (1995) with a w; 
string ${ }^{7 \mathrm{~B}}, \mathrm{P}\left[\mathrm{w}^{+}, \mathrm{Hs}\right.$-string $] / \mathrm{TM} 3$ stock using heat pulses to trigger synchronous progression through mitosis 14.

\section{Fly stocks}

The Cyclin A alleles CycA ${ }^{\text {neo114 }}$ and CycA C8LR1, a complete loss of function allele, and $\operatorname{Df}(2 \mathrm{R}) 59 \mathrm{AB}$, which deletes the Cyclin B gene, have been described previously (Knoblich and Lehner 1993), whereas the deficiency $\operatorname{Df}(2 \mathrm{R}) 599-5$ will be described elsewhere. With a PCR assay (Knoblich and Lehner 1993) using Cyclin B3-specific primers and Cyclin A-specific primers for positive control amplifications, we determined that the Cyclin B3 gene is deleted by the deficiency Df(3R)XTA1 that had to be kept over the duplication Dp(3;3)SuM (3)w13 because this deficiency also deletes a Minute locus. In addition, this deficiency also deletes the tolloid ${ }^{+}$gene, which is required for wild-type gastrulation (Shimell et al. 1991). To avoid the severe morphological abnormalities resulting in homozygous deficient embryos, we introduced the tolloid ${ }^{+}$transgene pM BO 1367 (Shimell et al. 1991) into the background of Df(3R)XTA1 for some experiments.

The P[w+, lacZ] insertion I(3)L6540 (Chang et al. 1993) was obtained from the Berkeley Drosophila Genome Project (Spradling et al. 1995) and found to be within the $5^{\prime}$ untranslated region of Cyclin B3 according to PCR experiments with a Pelement-specific and a number of Cyclin B3-specific primers. Flies homozygous for this insertion (al so designated as $\mathrm{CycB}^{1}$ ) eccl osed after a devel opmental del ay of 2 days and were found to be female sterile. $\mathbf{w}^{-}$derivatives of this chromosome were isolated after mobilizing the insertion with $\mathrm{P}\left[\mathrm{ry}^{+}, \Delta 2-3\right](99 \mathrm{~B})$. The Cyclin $\mathrm{B} 3$ region in $\mathrm{w}^{-}$derivatives associated with female sterility in homozygotes was analyzed by PCR experiments using P-element-specific and Cyclin B3-specific primers.

For the isolation of Cyclin B null alleles, we started with the P-element insertion M 95 that was isolated and found to be in the Cyclin B gene and kindly provided by $\mathrm{Y}$. Jiang and C. Dambly-Chaudiere (University of Montpellier II, France). The M 95 insertion was backcrossed to $w$ flies for six generations to remove the weak P-cytotype characteristics present in the original stock. Flies homozygous for the resulting chromosome with the M95 insertion (designated as $\mathrm{CycB}^{1}$ ) were fertile in both sexes. The imprecise excisions $\mathrm{CycB}^{2}$ and $\mathrm{CycB}^{3}$ were identified using the same strategy described above for Cyclin B3.

Cyclin $\mathrm{B}^{+}$and Cyclin $\mathrm{B}^{+}$transgenes $\left(\mathrm{P}_{\mathrm{w}} \mathrm{w}^{+}, \mathrm{CycB}^{+}\right]$and $\mathrm{P}\left[\mathrm{w}^{+}\right.$, $\left.\mathrm{CycB3}^{+}\right]$) were obtained after P-element-mediated germ-line transformation with CaSpeR 4 (Pirrotta 1988) constructs carrying either a 10-kb genomic Cyclin B fragment or a 9-kb genomic Cyclin B3 fragment.

\section{Acknowledgments}

We thank T. Laverty, C. Dambly-Chaudiere, and M. O'Connor for providing fly stocks, Eva-M aria IIIgen for technical help, and A. Wolf for comments on the manuscript. This research was supported by the Deutsche Forschungsgemeinschaft (DFG Le 987/2-1).

The publication costs of this article were defrayed in part by payment of page charges. This article must therefore be hereby marked 'advertisement' in accordance with 18 USC section 1734 solely to indicate this fact.

\section{References}

Baldin, V. and B. Ducommun. 1995. Subcellular localization of human weel kinase is regulated during the cell cycle. J. Cell Sci. 108: 2425-2432.
Brown, N.H. and F.C. Kafatos. 1988. Functional cDN A libraries from Drosophila embryos. J. Mol. Biol. 203: 425-437.

Chang, Z., B.D. Price, S. Bockheim, M.J. Boedigheimer, R. Smith, and A. Laughon. 1993. Molecular and genetic characterization of the Drosophila tartan gene. Dev. Biol. 160: 315-332.

Dal by, B. and D.M. Glover. 1992. 3' non-translated sequences in Drosophila cyclin B transcripts direct posterior pole accumulation late in oogenesis and perinuclear association in syncytial embryos. Development 115: 989-997.

-_- 1993. Discrete sequence el ements control posterior pole accumulation and translational repression of maternal cyclin B RN A in Drosophila. EMBO J. 12: 1219-1227.

Gallant, P. and E.A. Nigg. 1992. Cyclin B2 undergoes cell cycledependent nuclear translocation and, when expressed as a non-destructible mutant, causes mitotic arrest in HeLa cells. J. Cell Biol. 117: 213-224.

- - - 1994. Identification of a novel vertebrate cyclin: Cyclin B3 shares properties with both A-type and B-type cyclins. EMBO J. 13: 595-605.

Glotzer, M., A.W. M urray, and M.W. Kirschner. 1991. Cyclin is degraded by the ubiquitin pathway. Nature 349: 132-138.

Heald, R., M. M CLoughlin, and F. M cKeon. 1993. Human wee-1 maintains mitotic timing by protecting the nucleus from cytoplasmically activated cdc2 kinase. Cell 74: 463-474.

Howe, J.A., M. Howell, T. Hunt, and J.W. N ewport. 1995. Identification of a devel opmental timer regulating the stability of embryonic cyclin A and a new somatic A-type cyclin at gastrulation. Genes \& Dev. 9: 1164-1176.

Jackman, M., M. Firth, and J. Pines. 1995. Human cyclins B1 and $\mathrm{B} 2$ are localized to strikingly different structures: B1 to microtubules, B2 primarily to the Golgi apparatus. EMBO J. 14: 1646-1654.

Jeffrey, P.D., A.A. Ruso, K. Polyak, E. Gibbs, J. Hurwitz, J. M assagué, and N .P. Pavletich. 1995. M echanism of CDK activation reveal ed by the structure of a cyclin A-CDK2 complex. Nature 376: 313-320.

King, R.W., R.J. Deshaies, J.-M. Peters, and M.W. Kirschner. 1996a. How proteolysis drives the cell cycle. Science 274: 1652-1658.

King, R.W., M. Glotzer, and M.W. Kirschner. 1996b. M utagenic analysis of the destruction signal of mitotic cyclins and structural characterization of ubiquitinated intermediates. Mol. Biol. Cell 7: 1343-1357.

Knoblich, J.A. and C.F. Lehner. 1993. Synergistic action of Drosophila cyclin $A$ and cyclin $B$ during the $G_{2}-M$ transition. EMBO J. 12: 65-74.

Knoblich, J.A., K. Sauer, L. Jones, H. Richardson, R. Saint, and C.F. Lehner. 1994. Cyclin E controls S phase progression and its downregulation during Drosophila embryogenesis is required for the arrest of cell proliferation. Cell 77: 107-120.

Kobayashi, H., E. Stewart, R. Poon, J.P. Adamczewski, J. Gannon, and T. Hunt. 1992. Identification of the domains in cyclin A required for binding to, and activation of, p34(cdc2) and p32(cdk2) protein-kinase subunits. Mol. Biol. Cell 3: 1279-1294.

Kreutzer, M.A., J.P. Richards, M.N. De Silva-Udawatta, J.J. Temenak, J.A. Knoblich, C.F. Lehner, and K.L. Bennett. 1995. Caenorhabditis elegans cyclin A-type and B-type genes: A cyclin A multigene family, an ancestral cyclin B3 and differential germline expression. J. Cell Sci. 108: 24152424.

Lehner, C.F. 1992. The pebble gene is required for cytokinesis in Drosophila. J. Cell Sci. 103: 1021-1030.

Lehner, C.F. and P.H. O'Farrell. 1989. Expression and function of Drosophila cyclin A during embryonic cell cycle progres- 
sion. Cell 56: 957-968.

- - - 1990. The roles of Drosophila cyclin A and cyclin B in mitotic control. Cell 61: 535-547.

Li, J., A.N. Meyer, and D.J. Donoghue. 1997. Nuclear localization of cyclin B1 mediates its biological activity and is regulated by phosphorylation. Proc. Natl. Acad. Sci. 94: 502-507.

Maridor, G., P. Gallant, R. Golsteyn, and E.A. Nigg. 1993. $\mathrm{N}$ uclear localization of vertebrate cyclin A correlates with its ability to form complexes with cdk catalytic subunits. J. Cell Sci. 106: 535-544.

Millar, J.B.A., J. Blevitt, L. Gerace, K. Sadhu, C. Featherstone, and P. Russell. 1991. P55cdc25 is a nuclear protein required for the initiation of mitosis in human cells. Proc. Natl. Acad. Sci. 88: 10500-10504.

Mueller, P.R., T.R. Coleman, A. Kumagai, and W.G. Dunphy. 1995. Myt1: A membrane-associated inhibitory kinase that phosphorylates cdc2 on both Threonine 14 and Tyrosine 15. Science 270: 86-90.

Pines, J. and T. Hunter. 1991. Human cyclin A and cyclin B1 are differentially located in the cell and undergo cell cycle dependent nuclear transport. J. Cell Biol. 115: 1-17.

- - - 1994. The differential localization of human cyclin A and cyclin $B$ is due to a cytoplasmic retention signal in cyclin B. EMBO J. 13: 3772-3781.

Pirrotta, V. 1998. Vectors for P-element transformation in Drosophila. In Vectors. A survey of cloning vectors and their uses (ed. R.L. Rodriguez and D.T. Denhardt), pp. 437-456. Butterworths, Boston, MA.

Raff, J.W., W.G.F. Whitfield, and D.M. Glover. 1990. Two distinct mechanisms localize cyclin B transcripts in syncytial Drosophila embryos. Development 110: 1249-1261.

Richardson, H.E., L.V. O'Keefe, S.I. Reed, and R. Saint. 1993. A Drosophila $G_{1}$-specific cyclin $E$ homolog exhibits different modes of expression during embryogenesis. Development 119: 673-690.

Sauer, K., J.A. Knoblich, H. Richardson, and C.F. Lehner. 1995. Distinct modes of cyclin E/cdc2c kinase regulation and $\mathrm{S}$ phase control in mitotic and endoreduplication cycles of Drosophila embryogenesis. Genes \& Dev. 9: 1327-1339.

Shimell, M.J., E.L. Ferguson, S.R. Childs, and M.B. O'Connor. 1991. The Drosophila dorsal-ventral patterning gene tolloid is related to human bone morphogenetic protein 1. Cell 67: 469-481.

Sigrist, S., H. Jacobs, R. Stratmann, and C.F. Lehner. 1995. Exit from mitosis is regulated by Drosophila fizzy and the sequential destruction of cyclins A, B and B3. EMBO J. 14: 4827-4838.

Spradling, A.C., D.M. Stern, I. Kiss, J. Roote, T. Laverty, and G.M. Rubin. 1995. Gene disruptions using P transposable el ements: An integral component of the Drosophila genome project. Proc. Natl. Acad. Sci. 92: 10824-10830.

Sweeney, C., M. Murphy, M. Kubelka, S.E. Ravnik, C.F. Hawkins, D.J. Wolgemuth, and M. Carrington. 1996. A distinct cyclin A is expressed in germ cells in the mouse. Development 122: 53-64.

Tsai, L.H., E. Harlow, and M. Meyerson. 1991. Isolation of the human cdk2 gene that encodes the cyclin-A-associated and adenovirus-Ela-associated p33 kinase. Nature 353: 174-177.

Verde, F., J.C. Labbé, M. Dorée, and E. Karsenti. 1990. Regulation of microtubule dynamics by cdc2 protein-kinase in cellfree extracts of Xenopus eggs. Nature 343: 233-238.

Verde, F., M. Dogterom, E. Stelzer, E. Karsenti, and S. Leibler. 1992. Control of microtubule dynamics and length by cyclin A-dependent and cyclin B-dependent kinases in Xenopus egg extracts. J. Cell Biol. 118: 1097-1108.

Whitfield, W.G.F., C. Gonzalez, E. Sanchez-Herrero, and D.M.
Glover. 1989. Transcripts of one of the two Drosophila cyclin genes become local ized in pole cells during embryogenesis. Nature 338: 337-340.

Whitfield, W.G.F., C. Gonzalez, G. Maldonado-Codina, and D.M. Glover. 1990. The A-type and B-type cyclins of Drosophila are accumulated and destroyed in temporally distinct events that define separable phases of the $\mathrm{G}_{2}-\mathrm{M}$ transition. EMBO J. 9: 2563-2572.

Yamashita, M., M. Yoshikuni, T. Hirai, S. Fukada, and Y. N agahama. 1991. A monoclonal antibody against the PSTAIR sequence of p34cdc2, catalytic subunit of maturation-promoting factor and key regulator of the cell cycle. Dev. Growth Differ. 33: 617-624. 


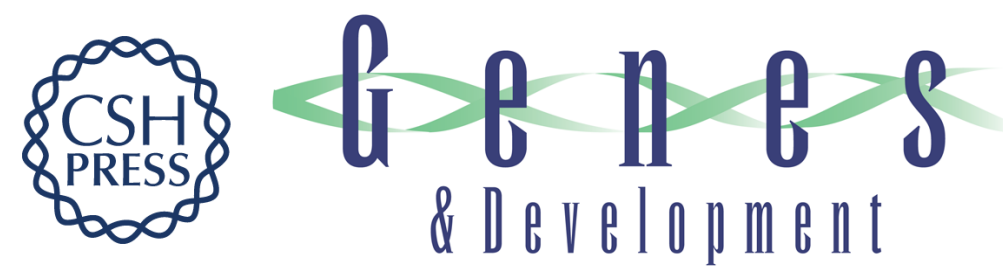

\section{Drosophila Cyclin B3 is required for female fertility and is dispensable for mitosis like Cyclin B}

Henning W. Jacobs, Jürgen A. Knoblich and Christian F. Lehner

Genes Dev. 1998, 12:

Access the most recent version at doi:10.1101/gad.12.23.3741

References This article cites 40 articles, 20 of which can be accessed free at: http://genesdev.cshlp.org/content/12/23/3741.full.html\#ref-list-1

License

Email Alerting

Receive free email alerts when new articles cite this article - sign up in the box at the top Service right corner of the article or click here.

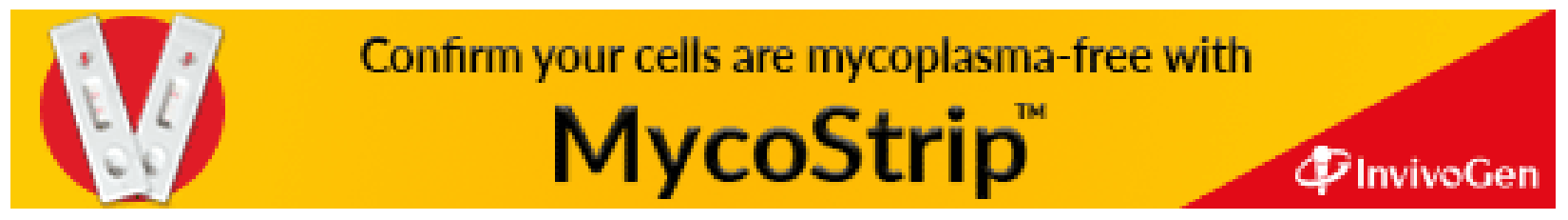

